\title{
Mycobacterium haemophilum
}

National Cancer Institute

\section{Source}

National Cancer Institute. Mycobacterium haemophilum. NCI Thesaurus. Code C86542.

A species of aerobic, Gram positive, rod shaped bacterium assigned to the phylum

Actinobacteria. This species is acid fast, nonmotile, catalase negative, requires haemin

for growth and is characterized by exclusively intracellular development. M. haemophilum

has an unknown reservoir and mode of transmission and is known to be pathogenic in immunocompromised individuals. 